\title{
Potential Evapotranspiration as a Means of Predicting Irrigation Timing in Greenhouse Tomatoes Grown in Peat Bags
}

\author{
J. Norrie, M.E.D. Graham, and A. Gosselin \\ Departement de Phytologie, Centre de Recherche en Horticulture, Universite Laval, Sainte Foy, Québec \\ G1V 7P4, Canada
}

Additional index words. Lycopersicon esculentum, nutrient solution, peat, Penman equation, tensiometers

\begin{abstract}
The use of potential evapotranspiration (PET) estimates to identify irrigation timing for greenhouse tomatoes (Lycopersicon esculentum Mill.) grown in peat-based substrate was evaluated for a spring and fall crop. PET (using the Penman equation) was calculated from leaf, wet and dry bulb temperatures, and incident and reflected photosynthetic photon flux. Substrate matric potential (SMP) was monitored continuously using electronic tensiometers. Two irrigation starting setpoints $(-4.5$ and $-6.5 \mathrm{kPa}$ SMP) and two nutrient solution electrical conductivity (EC) treatments (1.5 and 3.0 $\mathbf{d S} \cdot \mathbf{m}^{-1}$ ) were factorially combined in a completely randomized design. Irrigation frequency was greater in treatments irrigated at $\mathbf{- 4 . 5}$ than at $\mathbf{- 6 . 5} \mathrm{kPa}$. The integral of calculated PET values was correlated with SMP for both experiments. Accumulated PET values were higher at the start of irrigation in the $-6.5-\mathrm{kPa}$ treatments for spring and fall crops. Nutrient solution EC did not influence irrigation frequency. Leaf pressure potential (LPP) was correlated to PETpredicted LPP $\left(r^{2}>0.56\right)$ in plants subjected to high EC, low $(-6.5 \mathrm{kPa})$ matric potential setpoint, or both treatments. PET and electronic tensiometer technology can be used jointly to improve irrigation management for tomatoes grown in peatbased substrates by more accurately responding to crop needs for water and nutrients.
\end{abstract}

The use of soilless culture for growing greenhouse crops has increased substantially over the last 20 years (Winsor, 1984). During this time, peat bags have been as productive as rockwool and nutrient film technology culture for producing tomatoes (Ouimet et al., 1990; Verwer, 1976). To improve irrigation scheduling in peat-based substrates, electronic tensiometers are now being used to automatically control irrigation based on substrate dryness (Gobeil et al., 1989; Lieth and Burger, 1989; Stockwin, 1990). Single-nutrient injection equipment also has been developed for use in recirculating culture systems that can be programmed to supply plants with differing nutrient solutions during the growing period to meet the changing demands during ontogeny; e.g., increased $\mathrm{K}$ during fruit development (Papadopoulos and Liburdi, 1989). These authors also noted that such automated irrigation systems could be improved further by accommodating for changes in crop water or nutrient requirements according to environmental conditions.

Above-ground environmental influences on crop water and nutrient requirements can be assessed using evapotranspiration models (Eliades and Orphanos, 1986; Pruitt et al., 1984; Tan, 1988; Tan and Fulton, 1980; Tan and Layne, 1981) and can be related to yield (Chiaranda and Serbi, 1981). Many of these models, however, base irrigation requirements solely on light, temperature, soil water potential, or chronology. Measurements of the major environmental variables controlling water and nutrient movement within the plant can indicate past and present crop needs (Stanghellini, 1981, 1987). Also, direct measurements of leaf water potential can indicate the relationship between the plant environment and the ability of the plant to absorb water and

Received for publication 23 Apr. 1992 Accepted for publication 5 June 1993. CRH publication no. 25. We are grateful for the technical support of R. Pouliot, J. Charbonneau, and R. Daigle. We also thank the Conseil de recherche en pêche et agro-alimentaire de Québec for its continuing financial support of this project. The cost of publishing this paper was defrayed in part by the payment of page charges. Under postal regulations, this paper therefore must be hereby marked advertisement solely to indicate this fact. nutrients (Pill and Lambeth, 1980; Rudich et al., 1981), even though the main resistance to water movement may be in the roots (Tinklin and Weatherly, 1966). More recently, Aikman and Houter (1990), using the Penman-Monteith equation for potential evapotranspiration (PET) estimates (Penman, 1948), constructed a model predicting the energy absorbed from incident total solar radiation in a glasshouse tomato crop. They also suggested several ways to improve crop nutrition based on the relationship between crop growth and environmental conditions: lowering greenhouse temperature during low-light conditions, increasing nutrient solution concentration during periods of reduced light, and heating the upper canopy to drive transpiration and nutrient supply to areas of the canopy receiving more light.

More-accurate PET models use estimates or measurements of the major environmental factors influencing plant water and nutrient uptake including net radiation, vapor pressure deficit, and the resistance to heat transfer (the Penman-Monteith equation assumes a wet leaf surface). An irrigation system could be designed to modify irrigation frequency and nutrient solution electrical conductivity (EC) according to environmental pressures using PET estimations. This would complement and improve current systems, especially for peat-based greenhouse cultures for which climate can be closely controlled. Such irrigation systems would slowly increase nutrient solution EC during periods of low PET and lower it during periods of high PET (within reasonable limits, e.g., 1.0 to $4.0 \mathrm{dS} \cdot \mathrm{m}^{-1}$ ) without inducing water stress or causing adverse osmotic effects. For tomatoes, this type of irrigation control would optimize leaf water potential (Campbell and Campbell, 1982) and meet growth demands by increasing the concentration of transported $\mathrm{Ca}$ in the xylem, thereby reducing fruit blossom-end rot (Aikman and Houter, 1990), a disorder associated with water stress, Ca deficiency, or both (Ehret and Ho, 1986). No irrigation system is currently available that uses both electronic tensiometer and PET technology in an integrated irrigation management system. However, before such a system is constructed for tomatoes grown in peat-based media, the relationship between PET and water and nutrient uptake must be evaluated. 
The objective of this study was to evaluate the performance of electronic tensiometers and the use of PET estimations (predicted from the Penman equation) in predicting irrigation timing for tomatoes grown in peat bags. This was done by examining the relationship between PET and irrigation frequency, measured by monitoring substrate matric potential (SMP), for treatments receiving different nutrient solution concentrations applied at different SMP setpoints.

\section{Materials and Methods}

'Caruso' tomato plants were grown in 24-liter peat bags containing 70 sphagnum peat : 30 perlite (v/v) (Allegro Gro-Bags; Premier Peat-Moss, Rivière-du-loup, Québec) in a double polyethylene greenhouse in Spring and Fall 1989. Plants were sown in late January for the spring experiment and early August for the fall, and were transplanted into peat bags 5 weeks after seeding. Plants were grown under natural light with the greenhouse temperature set at $22 \mathrm{C}$ during the day and $18 \mathrm{C}$ at night. Several 2-cm-long slashes were placed along the ends and sides of the peat bags to facilitate drainage and prevent water logging. In a factorial experiment, two nutrient solutions with an EC of 1.5 or $3.0 \mathrm{dS} \cdot \mathrm{m}^{-1}$ (Table 1) were applied to plants at tensiometer-measured SMP setpoints of -4.5 or $-6.5 \mathrm{kPa}$ using a completely randomized design with seven replications. Each independent experimental unit consisted of one peat bag containing three plants, giving an overall planting density of 3.2 plants $/ \mathrm{m}^{2}$. Depending on the treatment, irrigation began when the SMP in two of the peat bags within respective treatments reached the irrigation setpoint and continued until SMPs were above (less negative than) $-0.7 \mathrm{kPa}$. Tensiometer setpoints were chosen to coincide with those used by greenhouse tomato producers $(-4.5 \mathrm{kPa})$ and the recommended lower threshold of the tensiometer pressure sensor $(-6.5 \mathrm{kPa})$. Irrigation solution EC values corresponded to levels above and below the 2.2- $\mathrm{dS} \cdot \mathrm{m}^{-1}$ average used by greenhouse tomato producers. When substrate salinity rose above $8 \mathrm{dS} \cdot \mathrm{m}^{-1}$, which usually occurred once every 3 days in the spring and once every week in the fall, the substrate was overwatered by $120 \%$ to $130 \%$ of bag capacity. Substrate solution $(50 \mathrm{ml} / \mathrm{bag})$ was extracted daily using an evacuated ceramic-tipped tensiometer to determine $\mathrm{pH}$ and $\mathrm{EC}$.

SMP was measured using four ceramic-tipped tensiometers

Table 1. Composition of nutrient solutions. ${ }^{\mathrm{Z}}$

\begin{tabular}{|c|c|c|}
\hline \multirow[b]{3}{*}{ Nutrient } & \multicolumn{2}{|c|}{ Nutrient composition ${ }^{\mathrm{y}}\left(\mathrm{mg} \cdot \mathrm{liter}^{-1}\right)$} \\
\hline & \multicolumn{2}{|c|}{ Solution electrical conductivity $\left(\mathrm{dS} \cdot \mathrm{m}^{-1}\right)$} \\
\hline & 1.5 & 3.0 \\
\hline $\mathrm{CaCO}_{3}$ & $362 \pm 12.5$ & $727 \pm 21.5$ \\
\hline $\mathrm{N}-\mathrm{NO}_{3}$ & $90.5 \pm 2.2$ & $216 \pm 10.3$ \\
\hline $\mathrm{P}$ & $39.2 \pm 1.7$ & $67.5 \pm 2.7$ \\
\hline $\mathrm{K}$ & $170 \pm 8.6$ & $363 \pm 11.8$ \\
\hline $\mathrm{Mg}$ & $27.7 \pm 0.8$ & $56.8 \pm 1.4$ \\
\hline $\mathrm{Ca}$ & $99.3 \pm 3.8$ & $198 \pm 7.0$ \\
\hline $\mathrm{Na}$ & $19.5 \pm 0.6$ & $30.3 \pm 0.7$ \\
\hline $\mathrm{Cu}$ & $0.1 \pm 0.01$ & $0.2 \pm 0.01$ \\
\hline $\mathrm{Fe}$ & $1.9 \pm 0.08$ & $4.4 \pm 0.13$ \\
\hline $\mathrm{Mn}$ & $0.5 \pm 0.02$ & $1.2 \pm 0.03$ \\
\hline $\mathrm{Zn}$ & $0.3 \pm 0.02$ & $0.6 \pm 0.02$ \\
\hline B & $0.2 \pm 0.01$ & $0.4 \pm 0.03$ \\
\hline
\end{tabular}

equipped with electronic pressure sensors (SenSym SX01DN; Banke Electronics, Scarborough, Ont.). Tensiometers were randomly placed into four peat bags within each treatment, and matric potential measurements were determined by an Osborne computer and DLX-100 controller-data acquisition system (AdTek, SainteFoy, Québec). The tensiometers were positioned horizontally $7 \mathrm{~cm}$ below the crown of the middle plant in each peat bag. A computer system monitored data and calculated the average of four tensiometer measurements within each treatment and recorded several greenhouse environmental variables.

PET calculations. Measured environmental characteristics included wet and dry bulb temperatures [by thermistors $( \pm 0.1 \mathrm{C})$ ] positioned within the canopy, average leaf temperature (average of four thermocouples $( \pm 0.1 \mathrm{C})$ positioned at random and touching one leaf within the canopy of each treatment), and incident and reflected radiation. Incoming and outgoing (reflected) photosynthetic photon flux (PPF) were initially measured using quantum sensors positioned above the canopy. Incoming global radiation was then calculated by multiplying PPF measurements by the average energy per photon in the 400- to $700-\mathrm{nm}$ waveband (conversion factor: $0.217 \mathrm{~J} \cdot \mu \mathrm{mol}^{-1} \cdot \mathrm{s}^{-1}$ ) and dividing by the ratio of energy in the 400- to 700-nm band to energy in the 300- to 4000$\mathrm{nm}$ band. These energy ratio values were calculated for incoming $(0.47)$ and reflected $(0.31)$ radiation from standard global and crop reflectance spectra at sea level (Monteith, 1973). Net infrared radiation was estimated using the Stephan-Boltzmann law: $\Phi=$ $\varepsilon \sigma T^{4}$, where $\varepsilon$ is the emissivity of the surface, $\sigma$ is the StephanBoltzmann constant $\left(5.67 \times 10^{-8} \mathrm{~W} \cdot \mathrm{m}^{-2} \cdot \mathrm{K}^{-4}\right)$ and $T$ is the surface temperature in degrees Kelvin. The radiant energy was therefore measured in Watts per square meter.

The difference between the average leaf temperature and the surroundings (the average between the air and dewpoint temperature) was used in the net infrared estimations. The inside surface of the greenhouse covering was usually water-saturated; therefore, a surface emissivity of 1 was assumed [blackbody radiator; Campbell (1986)]. PET then was calculated using the Penman equation described by Campbell (1986). The Penman equation can be written as

$$
\lambda E_{p}=\left\{s R n+\left[\left(\rho \mathrm{c}_{p}\left(\mathrm{e}_{\mathrm{sa}}-\mathrm{e}_{\mathrm{a}}\right)\right)\left(\mathrm{r}_{\mathrm{H}}\right)^{-1}\right]\right\}[\mathrm{s}+\gamma]^{-1}
$$

using the following variables: $\lambda E_{p}=\operatorname{PET}\left(\mathrm{W} \cdot \mathrm{m}^{-2}\right.$; unit becomes $\mathrm{J} \cdot \mathrm{m}^{-2}$ if integrated over time; $\lambda$ is the latent heat of water vaporization in $\mathrm{J} \cdot \mathrm{g}^{-1}$ ); $s=$ slope of saturation vapor density curve (at air temperature; $\left.\mathrm{kPa} \mathrm{C}^{-1}\right) ; R n=$ net amount of global radiation received at leaf surface $\left(\mathrm{W} \cdot \mathrm{m}^{-2}\right) ; \rho \mathrm{c}_{p}=$ volumetric heat capacity of air $\left(1200 \mathrm{~J} \cdot \mathrm{m}^{-3} \cdot \mathrm{K}^{-1}\right.$ at $\left.20 \mathrm{C}\right) ; \mathrm{e}_{\mathrm{sa}}=$ saturation vapor pressure (at air temperature; $\mathrm{kPa}) ; \mathrm{e}_{\mathrm{a}}=$ current vapor pressure (at air temperature; $\mathrm{kPa}) ; \mathrm{r}_{\mathrm{H}}=$ resistance to heat transfer $\left(45 \mathrm{~s} \cdot \mathrm{m}^{-1}\right.$, calculated from estimates of leaf diameter and greenhouse air movement; Campbell, 1986); and $\gamma=$ the thermodynamic psychrometric constant $\left(0.066 \mathrm{kPa} \cdot \mathrm{C}^{-1}\right)$.

These calculated values and tensiometer readings were recorded every minute, with average values calculated every $20 \mathrm{~min}$ of every day for both experiments. PET estimates also were integrated over 20-min periods. Average values of recorded environmental variables were calculated for season and time of day within each season. Actual evapotranspiration (AET) was estimated using daily irrigation measurements (irrigation minus drainage) averaged over the whole season.

Leaflet pressure potential (LPP) measurements. Leaflets were cut from just above the fifth truss (same height) of experimental plants within each treatment and were placed directly into a plastic 
folder to reduce water loss $(<30 \mathrm{sec}$ between excision and measurement) before being placed in the pressure chamber (Spomer, 1985) to estimate LPP. The LPP of two leaflets was measured from each treatment each hour for 1 spring and 1 fall day. Multiple regression analysis was carried out on the data using current PET, integrated PET (INTPET) since the last irrigation, and the average LPP measured within each treatment.

\section{Results and Discussion}

Recorded leaf and air temperatures, vapor pressure deficits, and net infrared radiation varied during the day in spring and fall experiments. The average daily net global radiation was much higher in spring (afternoon average: $\left.356 \mathrm{~W} \cdot \mathrm{m}^{-2}\right)$, than in fall $(103$ $\left.\mathrm{W} \cdot \mathrm{m}^{-2}\right)$. PET calculations resulted in daily $(24 \mathrm{~h})$ average values of $134 \mathrm{~W} \cdot \mathrm{m}^{-2}$ for spring and $95 \mathrm{~W} \cdot \mathrm{m}^{-2}$ for fall. However, as expected,

Table 2. Effects of nutrient solution electrical conductivity (EC) and substrate matric potential (SMP) setpoint on fruit yield of greenhouse tomato.

\begin{tabular}{|c|c|c|c|c|c|}
\hline \multicolumn{2}{|c|}{ Treatment } & \multirow{2}{*}{\multicolumn{2}{|c|}{$\begin{array}{c}\begin{array}{c}\text { Total fruit } \\
\text { yield }\end{array} \\
\left(\mathrm{kg} \cdot \mathrm{m}^{-2}\right)\end{array}$}} & \multirow{2}{*}{\multicolumn{2}{|c|}{$\begin{array}{c}\begin{array}{c}\text { Marketable } \\
\text { fruit wt }\end{array} \\
\text { (g/fruit) }\end{array}$}} \\
\hline \multirow{2}{*}{$\frac{\mathrm{SMP}}{(\mathrm{kPa})}$} & \multirow{2}{*}{$\frac{\mathrm{EC}}{\left(\mathrm{dS} \cdot \mathrm{m}^{-1}\right)}$} & & & & \\
\hline & & Spring & Fall & Spring & Fall \\
\hline-4.5 & 1.5 & 26.69 & 11.07 & 185 & 206 \\
\hline-4.5 & 3.0 & 24.24 & 10.17 & 175 & 193 \\
\hline-6.5 & 1.5 & 26.60 & 9.92 & 190 & 200 \\
\hline-6.5 & 3.0 & 24.67 & 9.54 & 172 & 190 \\
\hline \multicolumn{6}{|c|}{ Significance } \\
\hline \multicolumn{2}{|c|}{$\mathrm{EC}$} & $*$ & NS & $* *$ & $*$ \\
\hline \multicolumn{2}{|c|}{ SMP } & NS & NS & NS & NS \\
\hline \multicolumn{2}{|c|}{$\mathrm{EC} \times \mathrm{SMP}$} & NS & NS & NS & NS \\
\hline
\end{tabular}

$\overline{\mathrm{Ns},{ }^{*}, * *}$ Nonsignificant or significant at $P \leq 0.05$ or 0.01 , respectively. Values are means of seven replications. reduced PET estimates were evident during the night $\left(<5 \mathrm{~W} \cdot \mathrm{m}^{-2}\right)$. Radiation measurements are a major constituent of the PET equation; therefore, the average daily profiles of PET and radiation measurements were similar during spring and fall.

The average daily maxima of PET and radiation were higher in the spring $\left(371 \mathrm{~W} \cdot \mathrm{m}^{-2}\right.$ and $405 \mathrm{~W} \cdot \mathrm{m}^{-2}$, respectively) than in the fall $\left(296 \mathrm{~W} \cdot \mathrm{m}^{-2}\right.$ and $281 \mathrm{~W} \cdot \mathrm{m}^{-2}$, respectively). Calculated average PET values were sometimes higher than measured net radiation values, a result indicating an energy gain due to greenhouse heating.

SMP setpoint did not significantly affect overall fruit yield or average fruit weight in the spring experiment (Table 2). Total fruit yields were higher in plants receiving the low than the high EC solution in the spring, but EC did not affect total fruit yield in the fall. The low EC solution resulted in greater average fruit weight than the high EC solution in both seasons.

Irrigation profiles. Figure 1 presents examples of the diurnal variation between profiles of SMP and changes in INTPET between irrigations within treatments. Plants from the two $-4.5-\mathrm{kPa}$ treatments received five irrigations during the $24 \mathrm{~h}$ indicated (corresponding to actual time). Irrigation periods can be identified by large increases (less negative) in SMP after tensiometers have reached the $-4.5-\mathrm{kPa}$ setpoint. The evolution of INTPET also followed the irrigation profile during the $24 \mathrm{~h}$. INTPET values were reset to zero after an irrigation to begin the integration process. Slower changes in matric potential and INTPET occurred during the night and early morning than during the day. SMP and PET profiles in treatments receiving solutions of the same EC were not significantly different; however, these profiles were changed by differences in the irrigation setpoint. Plants from treatments irrigated at $-6.5 \mathrm{kPa}$ generally received only two irrigations daily.

INTPET for both treatments irrigated at $-4.5 \mathrm{kPa}$ was 2000 to $4000 \mathrm{~kJ} \cdot \mathrm{m}^{-2}$ when irrigation started (Fig. 1). Average PET was lower for each of the five irrigations at $-4.5 \mathrm{kPa}$ with $3.0 \mathrm{dS} \cdot \mathrm{m}^{-1}$ than with $1.5 \mathrm{dS} \cdot \mathrm{m}^{-1}$. This was a result of higher average SMP $(-4.1$ $\mathrm{kPa}$ ) with $3.0 \mathrm{dS} \cdot \mathrm{m}^{-1}$ (Fig. 1B) than with $1.5 \mathrm{dS} \cdot \mathrm{m}^{-1}$ (Fig. 1A), thereby reducing the integration period before irrigation. The $-4.5-$
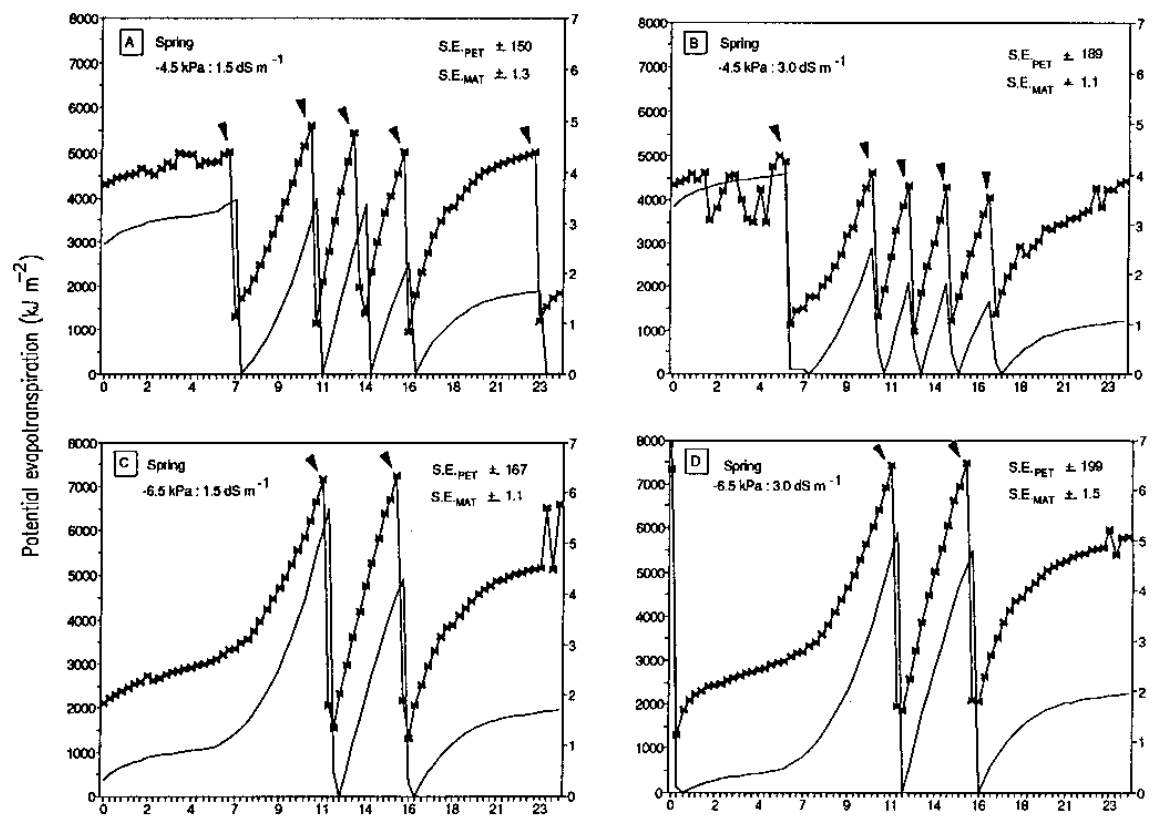

Hours

Fig. 1. Diurnal profile of peat substrate matric potential $(\mathrm{x}-\mathrm{x})$ and the accumulating potential evapotranspiration (solid line) for treatments: (A) $-4.5 \mathrm{kPa}, 1.5 \mathrm{dS} \cdot \mathrm{m}-$ ${ }^{1} ;(\mathbf{B})-4.5 \mathrm{kPa}, 3.0 \mathrm{dS} \cdot \mathrm{m}^{-1} ;(\mathbf{C})-6.5 \mathrm{kPa}, 1.5 \mathrm{dS} \cdot \mathrm{m}^{-1}$; and $(\mathbf{D})-6.5 \mathrm{kPa}, 3.0 \mathrm{dS} \cdot \mathrm{m}^{-1}$. SE of the mean is given for the integrated potential evapotranspiration $\left(\mathrm{SE}_{\mathrm{PET}}\right)$, and the peat matric potential $\left(\mathrm{SE}_{\mathrm{MAT}}\right)$, for each treatment. Arrows indicate start of irrigation. 

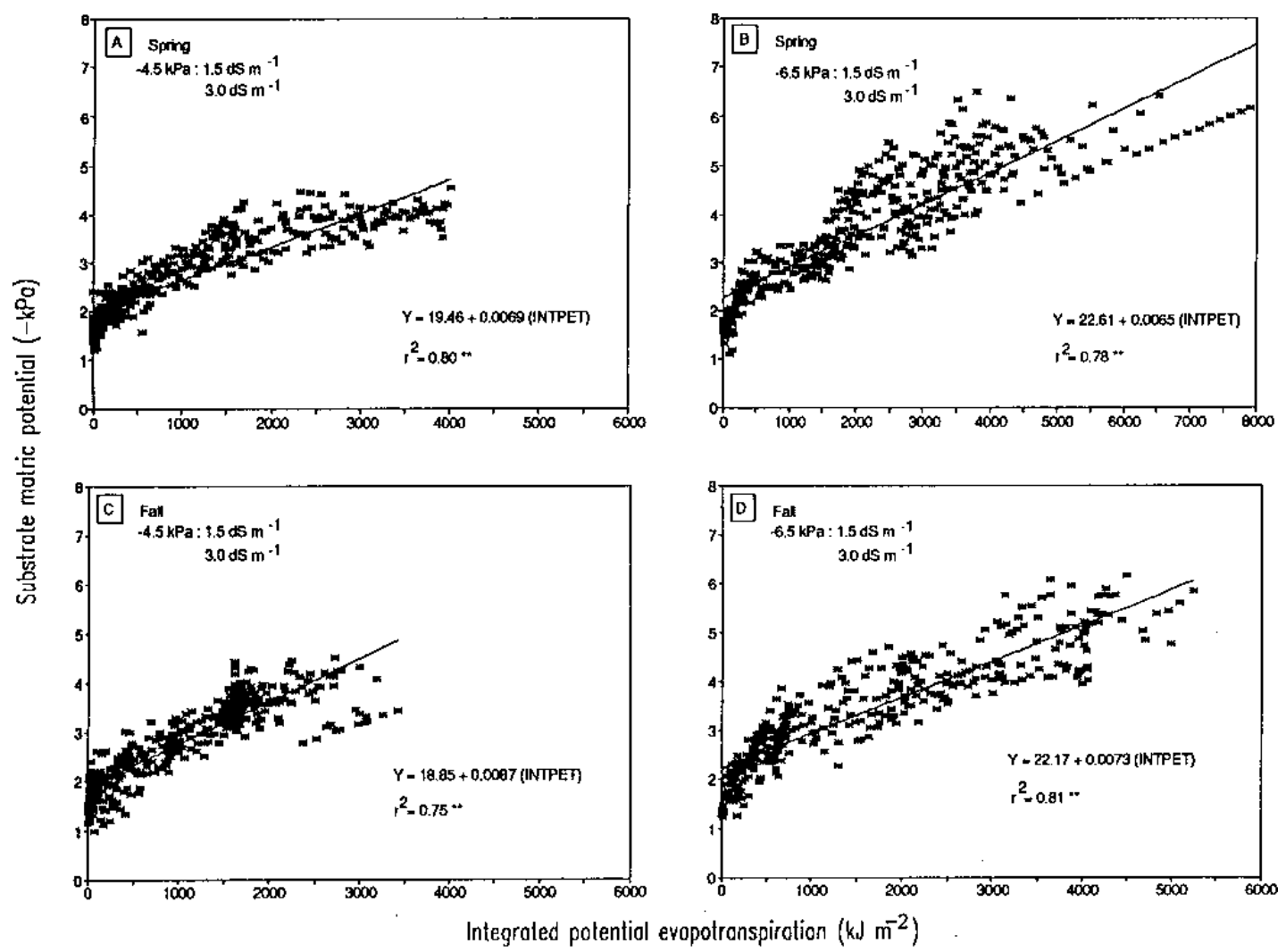

Fig. 2. Relationship between actual and predicted (solid line) substrate matric potential and the integrated potential evapotranspiration (INTPET) between irrigations for spring $(\mathbf{A}$ and $\mathbf{B})$ or fall $(\mathbf{C}$ and $\mathbf{D})$. Data was averaged over electrical conductivity treatments for each matric potential setpoint within each season and were compiled over 2 weeks.

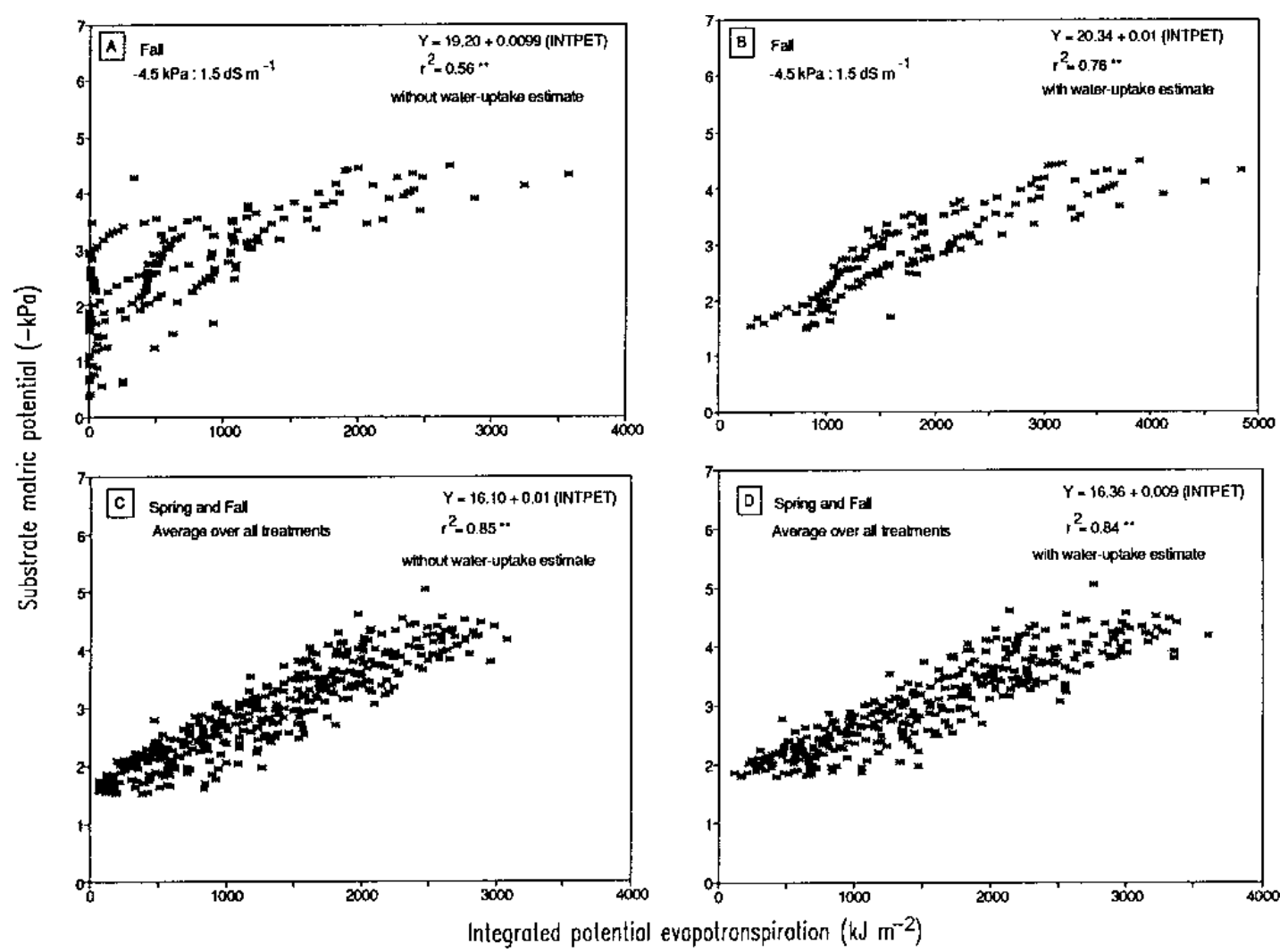

Fig. 3. Relationship between peat substrate matric potential and integrated potential evapotranspiration (INTPET), before and after estimations accounting for nightly water uptake $\left(15 \mathrm{~g} \cdot \mathrm{h}^{-1} \cdot \mathrm{m}^{-2}\right)$. Data are presented for both a single treatment over 3 days $(\mathbf{A}$ and $\mathbf{B})$ and averaged over all four treatments for spring and fall for 2 weeks $(\mathbf{C}$ and $\mathbf{D})$. 
$\mathrm{kPa}, 3.0-\mathrm{dS} \cdot \mathrm{m}^{-1}$ treatment resulted in five irrigations by 17:00 $\mathrm{HR}$, while the $-4.5-\mathrm{kPa}, 1.5-\mathrm{dS} \cdot \mathrm{m}^{-1}$ treatment did not receive the fifth one until 23:00 HR because the $-4.5-\mathrm{kPa}, 3.0-\mathrm{dS} \cdot \mathrm{m}^{-1}$ treatment received irrigation 1 to $1.5 \mathrm{~h}$ earlier in the morning. After 17:00 HR, PET declined, thereby prolonging the time necessary for the -4.5 $\mathrm{kPa}, 1.5-\mathrm{dS} \cdot \mathrm{m}^{-1}$ treatment to reach the irrigation SMP setpoint. Although small differences in daily irrigation profiles were evident, the average INTPET at irrigation did not differ significantly within these two treatments (Fig. $1 \mathrm{~A}$ and B) during the spring experiment, with values of $2642 \pm 125$ and $2669 \pm 204 \mathrm{~kJ} \cdot \mathrm{m}^{-2}$, respectively. Slight variance in substrate matric potentials between different EC treatments within a kPa treatment possibly was due to differential substrate drying caused by peat bag location in the greenhouse. In our experiment, two tensiometers indicating an SMP at the threshold level were required to begin irrigation. If the average SMP reading of all four tensiometers was used to start irrigation, the average might deviate from the desired irrigation SMP setpoint.

Treatments irrigated at $-6.5 \mathrm{kPa}$ (Fig. $1 \mathrm{C}$ and D) yielded INTPET values of 5000 to $6500 \mathrm{~kJ} \cdot \mathrm{m}^{-2}$. Higher accumulated PET estimates were found in these treatments before irrigation began, and irrigation was less frequent. Average seasonal INTPET values at irrigation of $4502 \pm 262$ and $4972 \pm 186 \mathrm{~kJ} \cdot \mathrm{m}^{-2}$ for the $-6.5-\mathrm{kPa}$, $1.5-\mathrm{dS} \cdot \mathrm{m}^{-1}$ and $-6.5-\mathrm{kPa}, 3.0-\mathrm{dS} \cdot \mathrm{m}^{-1}$ treatments respectively, were not significantly different. Plants from fall treatments received only one daily irrigation and, although irrigations started at different times, INTPET and SMP values followed each other closely (data not shown). Average fall values for INTPET at irrigation were $2316 \pm 103$ for the $-4.5-\mathrm{kPa}, 1.5-\mathrm{dS} \cdot \mathrm{m}^{-1}$ treatment and 5156 $\pm 271 \mathrm{~kJ} \cdot \mathrm{m}^{-2}$ for the $-6.5-\mathrm{kPa}, 3.0-\mathrm{dS} \cdot \mathrm{m}^{-1}$ treatment. However, as in the spring experiment, solution EC did not affect irrigation frequency significantly.

PET and substrate tensions were related linearly for all treatments (Fig. 2). Similar linear relationships also have been found between global radiation and transpiration in peppers (Capsicum annuиm L.), tomatoes, and cucumbers (Cucumis sativus L.) (de Graff and van den Ende, 1981). SMP profiles taken at 20-min intervals and accumulated over 2 weeks were averaged for treatments receiving different irrigation solution EC, but with the same irrigation setpoints. In both seasons, SMP and PET were closely related at less than $-2.0 \mathrm{kPa}\left(r^{2}=0.80\right)$. The more negative the preprogrammed irrigation setpoints, the higher the accumulated PET at irrigation. The PET-SMP relationship varied within each season and with irrigation setpoint, but $r^{2}$ values were always $>0.75$ when examined over periods longer than 1 week.

Water absorption under low PET. During times of reduced or negligible PET (i.e., at night), an estimated water uptake of 15 $\mathrm{g} \cdot \mathrm{h}^{-1} \cdot \mathrm{m}^{-2}$ was added to the INTPET measurements to linearize the relationship between PET and substrate water potential and to account for water absorption at night (Fig. 3). An example of this transformation was carried out over 3 days for the $-1.5-\mathrm{kPa}, 3.0$ $\mathrm{dS} \cdot \mathrm{m}^{-1}$ treatment. The relationship between INTPET and substrate water potential was improved over short time intervals ( $<3$ days; $r^{2}=0.56$ to 0.76 ; Fig. $3 \mathrm{~A}$ and $\mathrm{B}$ ) by including this water uptake estimate but was not improved over longer periods ( $>2$ weeks; $r^{2}$ $=0.84$; Fig. $3 \mathrm{C}$ and D).

The ratio between seasonally averaged AET (from daily drainage and irrigation measurements) and PET rates ranged from 0.60 to 0.78 in the spring and 0.53 to 0.81 in the fall. PET values were higher because they predict potential rates by assuming open stomates and little or no diffusional resistance (wet leaf surfaces) per unit surface area (Campbell, 1986; Monteith, 1973). Differences between PET and AET can induce some variability in the PET-SMP relationship. However, environmental conditions affecting PET also can affect AET. Further, environmental conditions affecting the physiology of the plant (e.g., stomatal opening) may influence AET. Irrigation scheduling may, therefore, be affected by differential substrate drying within and between EC, setpoint treatments, or both, and may in turn affect PET integration between irrigations.

Leaf water status. A series of pressure potential measurements was conducted to determine the effect of PET and INTPET on LPP during cloudless test days in spring and fall. To examine the effects of PET on LPP, a multiple regression equation was constructed for each treatment using the PET at the moment of LPP measurement and the integral of PET since the last irrigation. The $-4.5-\mathrm{kPa}, 1.5-$ $\mathrm{dS} \cdot \mathrm{m}^{-1}$ treatment showed no relationship between actual LPP and PET; however, the relationship was significant $(P<0.05)$ for the $-4.5-\mathrm{kPa}, 3.0-\mathrm{dS} \cdot \mathrm{m}^{-1}$ treatment, with $r^{2}=0.61$ and 0.56 for spring and fall, respectively (Table 3 ). The respective $r^{2}$ values increased to 0.61 and 0.62 in the spring and 0.71 to 0.79 in the fall for the $3.0-\mathrm{kPa}, 1.5-\mathrm{dS} \cdot \mathrm{m}^{-1}$ and $3.0-\mathrm{dS} \cdot \mathrm{m}^{-1}$ treatments.

Our results suggest that the relationship between LPP and PET improved in plants supplied with a more concentrated nutrient solution or irrigated at a lower SMP. Thus, when plants are placed under greater water stress (higher substrate solution salt concentration or lower SMP), there was improved ability to predict plant water stress in the plant as a function of PET. Rudich et al. (1981) found LPP to be affected more by aerial atmospheric factors in well-irrigated field tomatoes but that soil water had a greater effect at less than $-20.0 \mathrm{kPa}$. Our results also suggest a close relationship between PET estimations and plant water and nutrient uptake. These results provide the basis for developing a system to irrigate with a higher-EC solution during periods of low PET (e.g., maximum $4.0 \mathrm{dS} \cdot \mathrm{m}^{-1}$ at PET $<100 \mathrm{~W} \cdot \mathrm{m}^{-2}$ ) and with less-concentrated solutions during periods of high PET (e.g., $1.0 \mathrm{dS} \cdot \mathrm{m}^{-1}$ at PET $>600 \mathrm{~W} \cdot \mathrm{m}^{-2}$ ), and increasing irrigation frequency during times of high PET. Irrigation control of this type is not possible

Table 3. Relationship between leaf water potential (Y) and potential evapotranspiration (PET) in greenhouse-grown tomatoes from spring and fall experiments as influenced by nutrient solution electrical conductivity (EC) and substrate matric potential (SMP).

\begin{tabular}{|c|c|c|c|c|c|}
\hline \multicolumn{2}{|c|}{ Treatment } & \multicolumn{2}{|l|}{ Spring } & \multicolumn{2}{|l|}{ Fall } \\
\hline $\begin{array}{l}\mathrm{EC} \\
\left(\mathrm{dS} \cdot \mathrm{m}^{-1}\right)\end{array}$ & $\begin{array}{l}\text { SMP } \\
(\mathrm{kPa})\end{array}$ & $\begin{array}{l}\text { Regression } \\
\text { equation }\end{array}$ & $r^{2}$ & $\begin{array}{l}\text { Regression } \\
\text { equation }\end{array}$ & $r^{2}$ \\
\hline 1.5 & -4.5 & $\mathrm{Y}=4.67+0.0021(\mathrm{PET})+0.00084\left(\right.$ INTPET $\left.^{\mathrm{z}}\right)$ & $0.22^{\mathrm{NS}}$ & $\mathrm{Y}=3.05+0.0037(\mathrm{PET})+0.00024(\mathrm{INTPET})$ & $0.20^{\mathrm{NS}}$ \\
\hline 3.0 & & $\mathrm{Y}=4.23+0.0052(\mathrm{PET})+0.00083($ INTPET $)$ & $0.61^{*}$ & $\mathrm{Y}=3.35+0.0072(\mathrm{PET})+0.00022(\mathrm{INTPET})$ & $0.56^{* *}$ \\
\hline 1.5 & -6.5 & $\mathrm{Y}=6.94+0.0020(\mathrm{PET})+0.00045(\mathrm{INTPET})$ & $0.61^{*}$ & $\mathrm{Y}=2.04+0.0083(\mathrm{PET})+0.00077(\mathrm{INTPET})$ & $0.71^{* *}$ \\
\hline 3.0 & & $\mathrm{Y}=6.61+0.0052(\mathrm{PET})+0.0014(\mathrm{INTPET})$ & $0.62^{*}$ & $\mathrm{Y}=2.79+0.0065(\mathrm{PET})+0.00021(\mathrm{INTPET})$ & $0.79^{* *}$ \\
\hline
\end{tabular}

${ }^{\mathrm{z} I N T P E T}=$ integral of the PET since the last irrigation.

Ns, ${ }^{* * *}$ Nonsignificant or significant at $P \leq 0.05$ or 0.01 , respectively. Two samples for leaf pressure potential measurements were taken from six and nine plants per treatment on spring and fall test days, respectively. 
without integrating PET and using tensiometer technology for peat-bag-grown tomatoes. Varying solution EC can optimize nutrient uptake and improve fruit quality by accommodating for changes in plant requirements for water and nutrients. This is most important in the case of some nutritional disorders (e.g., blossomend rot due to $\mathrm{Ca}$ deficiency). Therefore, PET-tensiometer technology is useful for predicting irrigation timing and for optimizing nutrient uptake in crops grown in peat-based media. By accounting for environmental effects on plant needs for water and nutrients, PET-tensiometer technology provides more efficient irrigation than current systems.

\section{Literature Cited}

Aikman, D.P. and G. Houter. 1990. Influence of radiation and humidity on transpiration: Implications for calcium levels in tomato leaves. J. Hort. Sci. 65:245-253.

Campbell, G.S. 1986. An introduction to environmental biophysics. Springer-Verlag, New York.

Campbell, G.S. and M.D. Campbell. 1982. Irrigation scheduling using soil moisture measurements: Theory and practice, p. 25-42. In: D. Hillel (ed.). Advances in irrigation. vol. 1. Academic Press, New York.

Chiaranda, F.Q. and G. Serbi. 1981. Effect of irrigation regime on yield and water consumption of greenhouse tomato grown in lysimeters. Acta Hort. 119:179-190.

de Graff, R. and J. van den Ende. 1981. Transpiration and evapotranspiration of the glasshouse crops. Acta Hort. 119:147-158.

Eliades, G. and P.I. Orphanos. 1986. Irrigation of tomatoes grown in unheated greenhouses. J. Hort. Sci. 61:95-101.

Ehret, D.L. and L.C. Ho. 1986. The effects of salinity on dry matter partitioning and fruit growth in tomatoes grown in nutrient film culture. J. Hort. Sci. 61:361-367.

Gobeil, G., M. Phénix, B. Anctil, L.-E. Parent, R. Lagacé and A. Gosselin. 1989. Système automatisé de contrôle de l'irrigation des milieux de culture à base de tourbe. Proc. Peat and Peatlands Symp.: Diversification and Innovation. vol. 2. p. 82-86.

Lieth, J.H. and D.W. Burger. 1989. Growth of chrysanthemum using an irrigation system controlled by soil moisture tension. J. Amer. Soc. Hort. Sci. 114:387-392.

Monteith, J.L. 1973. Principles of environmental physics. American
Elsevier, New York.

Ouimet, R., J. Charbonneau, L.-E. Parent, J. Blain, P. Joyal, and A. Gosselin. 1990. Effets de la composition du substrat tourbeux et du volume des sacs de culture sur la productivité de la tomate de serre. Can. J. Plant Sci. 70:585-590.

Papadopoulos, A.P. and N. Liburdi. 1989. The "Harrow fertigation manager"-A computerized multifertilizer injector. Acta Hort. 260:255-265.

Penman, H.L. 1948. Natural evaporation from open water, bare soil and grass. Proc. Roy. Met. Soc. London. 198:120-145.

Pill, W.G. and V.N. Lambeth. 1980. Effects of soil water regime and nitrogen form on blossom-end rot, yield, water relations, and elemental composition of tomato. J. Amer. Soc. Hort. Sci. 105:730-734.

Pruitt, W.O., E. Fereres, D.W. Henderson, and R.M. Hagan. 1984. Evapotranspirational losses of tomatoes under drip and furrow irrigation. Calif. Agr. 38:10-11.

Rudich, J., E. Rendon-Poblete, M.A. Stevens, and A.-I. Ambri. 1981. Use of leaf water potential to determine water stress in field-grown tomato plants. J. Amer. Soc. Hort. Sci. 106:732-736.

Spomer, L.A. 1985. Techniques for measuring plant water. HortScience 20:1021-1028.

Stanghellini, C. 1981. Estimation of energy requirement for evaporation in greenhouses. Acta Hort. 115:693-699.

Stanghellini, C. 1987. Transpiration of greenhouse crops: An aid to climate management. IMAG Press, Wageningen, Netherlands.

Stockwin, W. 1990. Let your plants do the watering. Greenhouse Grower $8: 20-22$

Tan, C.S. 1988. Water supply and irrigation. Acta Hort. 228:91-96.

Tan, C.S. and J.M. Fulton. 1980. Ratio between evapotranspiration of irrigated crops from floating lysimeters and class A pan evaporation. Can. J. Plant Sci. 60:197-201.

Tan, C.S. and R.E.C. Layne. 1981. Application of a simplified evapotranspiration model for predicting irrigation requirements of peach HortScience 16:172-173.

Tinklin, R. and P.E. Weatherly. 1966. On the relationship between transpiration rate and leaf water potential. New Phytol. 67:509-517.

Verwer, F.L.J.A.W. 1976. Growing horticultural crops in rockwool and nutrient film. IWOSC Proc. p. 107-119.

Winsor, G. 1984. NFT and other modern hydroponic systems. Symposium international sur la serriculture, Québec. Conseil des productions végétales du Québec. p. 229-248. 